\title{
O curso de Sânscrito
}

\section{MARIA VALÍRIA ADERSON DE MELLO VARGAS}

7 raçar um quadro histórico dos estudos de sânscrito desenvolvidos na Faculdade de Filosofia, Letras e Ciências Humanas da Universidade de Sáo Paulo consiste, sem dúvida, em mostrar que houve, ao longo de vinte e seis anos, efetiva evoluçäo, que configura os objetivos maiores de uma universidade, aberta, como deve ser, à renovação de currículos, de programas de disciplinas, de linhas de pesquisa, de criação e desenvolvimento de projetos interdisciplinares etc.

Nessa perspectiva, pode-se afirmar que a preocupação do quadro docente, desde a fundação do Curso de Língua e Literatura Sânscrita, foi caracterizá-lo e promovê-lo como um curso acadêmico integrado, antes de tudo, na tradição de seriedade que rege a investigaçáo científica daquela faculdade e situá-lo como uma dentre tantas possibilidades de formação de saber oferecidas pela Universidade de São Paulo.

Assim, as linhas de pesquisa desenvolvidas na área de Língua e Literatura Sânscrita privilegiam o estudo da gramática do sânscrito nos seus padróes cultos, a análise das teorias da linguagem engendradas na Índia antiga, o exame dos tratados de poética e dos recursos estilísticos detectados nos textos da literatura sânscrita, a observação acurada da história da literatura e dos gêneros literários manifestados naquela cultura e o desenvolvimento de crítica ao modo como o sânscrito foi e é observado pelos estudiosos do Ocidente. O objetivo maior é tornar esses estudos engajados nas linhas mais gerais de pesquisa de várias áreas afins, para que favoreçam o desenvolvimento das teorias da Lingüística Geral, da Semiótica, da Historiografia Lingüística, da Lingüística Histórica, dos chamados estudos clássicos, e, ao mesmo tempo, dos estudos sobre as culturas antigas, modernas e contemporâneas dos povos da Ásia e dos outros continentes.

Criado em 1968 - como bacharelado - no conjunto das áreas relacionadas aos estudos orientais, com quarenta vagas distribuídas entre duas turmas em dois períodos, o curso de sânscrito da FFLCH da USP teve como fundador emérito o saudoso professor Eurípedes Simóes de Paula - a quem deveu não apenas a criação, mas a contínua assistência, o estímulo e auxílios posteriores - e, como primeiros docentes encarregados das aulas, a também saudosa professora Maria Luísa Fernandez Miazzi e o professor Izidoro Blikstein, ambos pertencentes à antiga Ca- 
deira de Filologia Românica da mesma faculdade, a quem competia ministrar, naquela fase inaugural, a parte de língua, justamente a que adquiriram no exterior (Estados Unidos e França, respectivamente), como subsídio ao estudo da Lingüística Indo-Européia. Graças à cooperação e ao esforço desses dois professores, que acumulavam a docência de outras disciplinas - Lingüística Indo-Européia e Filologia Românica - , o curso de sânscrito se implementava no conjunto das demais áreas de Letras e contava com a expressiva participaçáo dos docentes e dos alunos, empenhados na tarefa de coletar obras e outros materiais relativos à literatura e à cultura sânscrita de modo a dar suporte aos estudos da língua.

Até 1977, o curso desenvolveu-se sob a coordenação da professora Miazzi que muito lutou pela expansảo dos estudos de sânscrito no Brasil e que se distinguiu pela criaçáo e desenvolvimento de linhas de pesquisa e de ensino e pela orientaçáo proporcionada aos trabalhos acadêmicos de grau de ex-alunos do próprio curso de sânscrito da USP que passavam a ser os docentes da área.

Essa formaçáo dos docentes permitiu a estratégica integraçáo do sânscrito nas grandes linhas de pesquisa da pós-graduaçáo da FFLCH da USP e foi, de certa forma, responsável pela reestruturaçáo que se processou na área de Língua e Literatura Sânscrita e resultou em uma nova fase dos estudos de sânscrito naquela faculdade.

Aliou-se a isso o fato de a realização dos projetos de interaçăo acadêmica daqueles docentes se dar, fora do âmbito da faculdade e da universidade, no contexto de reuniōes científicas organizadas por sociedades acadêmicas que contam com a participação de professores das áreas de Grego, Latim, História Antiga, Arqueologia, Filosofia e Lingüística, notadamente no conjunto dos chamados estudos clássicos, em que o sânscrito tem tido lugar privilegiado, nos últimos séculos, na composição do tripé lingüístico dos estudos de gramática e lingüística comparadas das línguas indo-européias. Esse novo campo de ação dos estudos de sânscrito resultou na transferência, em 1990, da área de Língua e Literatura Sânscrita do Departamento de Línguas Orientais para o Departamento de Letras Clássicas e Vernáculas da mesma faculdade, com o objetivo de integrarem-se os programas de sânscrito aos de grego e de latim.

Não se modificou, é claro, a reflexão que se faz a respeito do interesse e da necessidade da existência de um curso de sânscrito no conjunto de Letras de uma universidade como a de São Paulo, patrocinadora maior dos estudos humanísticos, entretanto, a manutençáo do bacharelado, dentro da nova visão de universidade que vinha e vem se 
impondo, teve de ser repensada. Assim, a partir de 1990, em atendimento à solicitação dos próprios docentes da área, não mais se ofereceram vagas de ingresso no bacharelado de sânscrito. Além disso, propôs-se que as disciplinas optativas oferecidas à época, nos dois turnos, fossem reestruturadas no sentido de se estabelecer um elenco orientado de programas de língua, literatura e cultura sânscritas, introdutórios, alguns, e outros mais específicos, sobre fatos peculiares de língua e sobre posturas filosóficas e estéticas manifestadas nos textos dos períodos védico, bramânico, épico e clássico da literatura sânscrita. Instituíramse, também em 1990, cursos de difusão cultural e de extensão universitária sobre temas relativos a diversos aspectos da cultura sânscrita, apoiados, de preferência, naqueles períodos básicos da literatura e que atendem principalmente aos interessados sem vínculos com a universidade.

Conservou-se, assim, o núcleo básico do conteúdo ministrado aos antigos ingressantes pelo vestibular, mas sem o ônus que os quatro anos do Bacharelado acarretavam à universidade, otimizando-se, ainda, o atendimento à demanda de prestação de serviços à comunidade. $\mathrm{E}$, ao mesmo tempo em que a área se liberava dos antigos problemas - número expressivo de vagas não preenchidas e reduzido número de formandos, por exemplo -, intensificava-se a execução de um projeto acadêmico voltado para a publicaçáo de artigos e ensaios relativos à cultura sânscrita ou indiana em geral. Hoje o projeto se implanta com a edição da revista Bbarata - Cadernos de Cultura Indiana, impressa pela FFLCH da USP, e também direcionado para a participação efetiva dos docentes nos trabalhos e nas publicações resultantes de congressos nacionais e internacionais promovidos pelas diversas associaçóes científicas às quais aqueles docentes se filiaram - Associaçáo Latino-Americana de Sanscritistas (Alas), International Association of Sanskrit Studies(IASS), Sociedade Brasileira de Estudos Clássicos (SBEC), Sociedade Brasileira para o Progresso da Ciência (SBPC), Grupo de Estudos Lingüísticos do Estado de São Paulo (GEL), Associação Latino-Americana de Estudos Afro-Asiáticos do Brasil (Aladaab), Associação Brasileira de Lingüística (Abralin) etc.

A reestruturação permitiu, ainda, que se incluíssem e se ampliassem, nos novos projetos e linhas de pesquisa, as antigas pretensóes de situar o sânscrito no âmbito dos estudos de Lingüística Indo-Européia, de Línguas Clássicas e de Lingüística Geral e resulta cada vez maior o envolvimento do sânscrito em várias frentes de produção científica.

Nesse quadro, é necessário lembrar a participação crescente daqueles docentes nas atividades de ensino, pesquisa e orientação ligadas à 
pós-graduação. Desde 1990, disciplinas relacionadas ao sânscrito compõem o Curso de Pós-Graduação em Lingüística - área de concentração em Semiótica e Lingüística Geral - por ora, em linhas de pesquisa mais específicas sobre Historiografia Lingüística e Lingüística Histórica, recentemente criadas dentro do projeto de reestruturação que se promove naquele curso de pós-graduação do Departamento de Lingüística da FFLCH da USP. E fundamental, por exemplo, a contribuição dos estudos de sânscrito para a sistematizaçáo do trabalho historiográfico em Lingüística, por meio de programas que pressupóem o exame, nas diferentes épocas históricas, de como se constituiu a ciencia gramatical. E, nas perspectivas da área de Lingüística Histórica, que deve enfatizar a questão da mudanfa na evoluçáo das línguas, integra-se, por exemplo, um programa que visa à análise dos mecanismos de organizaçáo morfológica e sintática do sânscrito, essencial para estudos posteriores e disciplinas que envolverão reflexóes mais aprofundadas a respeito dos modos de produção de sentido observados nos textos sânscritos e que deverão contribuir para os estudos mais recentes relacionados, em geral, à análise da organizaçáo discursiva. Desperta, portanto, promissor e abrangente um campo de especialização para alunos de pósgraduação que eventualmente serão os futuros docentes da área de Língua e Literatura Sânscrita.

Ainda como resultado do enlace dos estudos de sânscrito com as várias frentes de produção do saber, desenvolve-se na área um projeto de pesquisa coletivo a respeito das concepçóes da linguagem na f́ndia antiga, com ênfase na análise das teorias lingüísticas presentes nos textos indianos de expressão sânscrita e que prevê, por exemplo, a tradução e o estudo da obra de Panini, freqüentemente mencionada nos tratados lingüísticos, mas ainda não examinada com a profundidade que seu conteúdo exige.

Esse envolvimento dos estudos de sânscrito com variados projetos e linhas de pesquisa, bem como a referida reestruturação que se processou na área provocaram, como era previsto, o aparecimento de alunos com características diferentes em relação aos que entravam pelo vestibular. Além dos que provêm dos vários cursos de Letras, freqüentam as disciplinas de sânscrito outros alunos da Faculdade de Filosofia, oriundos, principalmente, dos Departamentos de História, Filosofia e Ciências Sociais e, ainda, de outros institutos e escolas da USP, com destaque para os da Física, da Biologia e da Politécnica. E cresce, de ano para ano, o número de pessoas que, não vinculadas à universidade, procuram o curso em razão do conteúdo curricular por ele oferecido, embora não visem à obtençăo de um diploma regular de Letras. 
Pode-se afirmar, para concluir essa breve trajetória, que o curso de sânscrito hoje se encontra mais organicamente integrado no conjunto das ofertas do Curso de Letras da FFLCH da USP, seja com o oferecimento de disciplinas optativas que podem funcionar como complementares para outras áreas, seja com a participaçáo de seus docentes nos programas de pós-graduaçăo de Lingüística e em outros projetos interdisciplinares da própria USP e de outras universidades brasileiras, seja, ainda, com a participação constante desses docentes em congressos nacionais e internacionais ou com o oferecimento de cursos de difusáo cultural que atendem aos interessados da comunidade. $O$ curso de sânscrito, afinal, atende plenamente aos interesses da Universidade, já que os mencionados estudos, projetos e linhas de pesquisa podem e devem promover a reflexão sobre questóes que transcendem o cotidiano da realidade brasileira e conseqüientemente fornecem dados para a compreensão e a eventual transformação dessa realidade.

Maria Valliria Aderson de Mello Vargas é professora do Departamento de Letras Clássicas e Vernáculas da Faculdade de Filosofia, Letras e Ciências Humanas da USP. 